\title{
Can a Natural Economy Operate in Macroeconomy? A Caution for Deviation from Natural Economy
}

\author{
Koji Akimoto 1
}

Received: 27 March 2015 / Accepted: 5 January 2016 / Published online: 15 February 2016

(C) Società Italiana degli Economisti (Italian Economic Association) 2016

\begin{abstract}
The fundamental problem issue of this paper is that a fundamental cause of economic crises, such as the dot-com bubble, the Lehman crash, or PIIGS, from which the current capitalist economy is suffering, lies in a large deviation from a natural economy. Any large deviation from the natural economy entails high risk. Akimoto (Int J Econ Sci III(4):1-37, 2014) proved this proposition. This leads to a question of whether a mechanism, in which a natural economy operates to begin with, exists in the macroeconomy. First, we adopt the definition by Pasinetti (Structural change and economic growth; a theoretical essay on the dynamics of the wealth of nation. Cambridge University Press, 1981) from a macroeconomic viewpoint, because it depends on the structure of the production process. However, there is no guarantee that the natural economy defined by Pasinetti (Structural change and economic growth; a theoretical essay on the dynamics of the wealth of nation. Cambridge University Press, 1981) operates in the macroeconomy. If Akimoto's (Int J Econ Sci III(4):137,2014 ) analysis is correct, we need to prove that a mechanism through which the natural economy operates does in fact exist in the macroeconomy. We construct a macroeconomic game with capitalists and workers as players. The macroeconomy involves circulating players' savings to investments via capital markets. This process constructs Kaldor's fundamental equation. We prove that a Nash equilibrium exists, which carries out a natural economy and balanced economic growth. In addition, the theoretical analysis demonstrates that Kaldor's fundamental equation, which is Keynesian, becomes an identity, i.e., $1=1$. This implies that the Keynesian equation brings about a classical result.
\end{abstract}

Akimoto (2014).

Koji Akimoto

akimoto_koji@kurume-u.ac.jp

1 Faculty of Economics, Kurume University, 1635 Mii-Machi, Kurume, Fukuoka 839-8502, Japan 
Keywords Non-corporative macroeconomic game $\cdot$ Natural economy Balanced economic growth · Kaldor's fundamental equation · Labor theory

JEL Classification $\quad \mathrm{B} 12 \cdot \mathrm{B} 16 \cdot \mathrm{E} 10 \cdot \mathrm{E} 12 \cdot \mathrm{C} 72 \cdot \mathrm{P} 10$

\section{Introduction}

This study examines whether a natural economy can operate in the macroeconomy. The fundamental problem issue of this paper is that a fundamental cause of economic crises, from which the current capitalist economy is suffering, lies in a large deviation from a natural economy. This leads us to ask if a mechanism exists in the macroeconomy through which the natural economy operates.

An overview of the core issue needed to discuss a natural economy will first be offered.

Two remarkable trends in the capitalist economy since the 1980s have been the rapid expansion of the world's financial assets and the corresponding rapid GDP increase in high asset areas. ${ }^{1}$ The expansion of money should be considered as destructive to the economy's balance (see Akimoto 2014). From an economic theory viewpoint, this destruction is considered to be a deviation from macroeconomic equilibrium and therefore a deviation from a natural economy. However the natural economy is not a synonym for macroeconomic equilibrium. Nonetheless, a natural economy, - despite differences in definitions between various viewpoints, involves an economic equilibrium. Therefore, taking a contraposition, deviation from such an equilibrium can be considered a deviation from a natural economy. Akimoto (2014) discusses the high risks entailed in the deviation from natural economy and concluded that human cannot control the economy artificially ignoring natural economy Thus, one of the important problems remaining to be investigated is whether a mechanism by which the natural economy operates does in fact exists in the macroeconomy.

At this stage, we should explore how the natural economy functions. As the economist Smith (1776) described, a market price fluctuates around the natural price. This fluctuation has two important implications. First, a natural economy constitutes the economy's basic structure. Therefore, studying the natural economy means analyzing the basic laws that underpin and control the economy. Second, any large deviation from the natural economy entails high risk. Such risks therefore provide an important alarm for controlling the economy without rigorous rules. We cannot artificially control the economy by ignoring the natural economy.

When we study the natural economy by Smith (1776), we should also analyze natural interest rates. After Smith, many economists tried to define a natural interest rate from macroeconomic viewpoint. First, we should highlight the definition by Wicksell (1898). Wicksell defined a natural interest rate as being neutral for a price level established in the real market. More precisely, it is the rate at which demand is equal to supply in the real market, making a capital market unnecessary. As is well known, this definition affected Keynes (1930). In his book, A Treatise on Money (1930), Keynes

\footnotetext{
${ }^{1}$ For instance, see http://www.meti.go.jp/report/tsuhaku2008/2008honbun/html/i1120000.html.
} 
constructed the fundamental equation whereby a natural interest rate was defined as a rate that made investment equal to savings. At the natural interest rate, the price level is equal to the monetary income per output paid for the production factors.

However, a situation wherein investment equals savings implies dependences on the shapes of both investment and saving functions. For instance, if an innovation is expected to occur, the expectation of this innovation will change the investment function and the natural interest rate will increase. In this case, no information is given with respect to developments in the production process. However, it is absolutely certain that the natural interest rate depends upon the structure of the production process.

Pasinetti (1981) proposed a different approach to that of Wicksell. Using an approach based on the theory of labour, Pasinetti concentrated on the structures of the production process and innovation. First, he began with the condition of full employment of labour and capital stock, using a vertically integrated analysis defined by the multi-sector model. Second, he introduced the concept of natural rate of profit and constructed a natural economy. Finally, he introduced financial assets to thenatural economy and proved the emergence of a rate of interest. After these preparations, Pasinetti defined the own-rate of interest for each commodity and rigorously analyzed the relation between the nominal rate of interest and real rates of interest (standard real rate of interest). After defining the concept of interest rates at each stage, he finally reached the definition of the natural rate of interest. ${ }^{2}$

From the above discussion, we see that the natural interest rates defined by Wicksell and Pasinetti are both representative and based on a macroeconomic equilibrium. Among these, we adopt the definition by Pasinetti because it depends on the structure of the production process. Therefore, the concept of natural economy in this study depends on definitions of both Smith (1776) and Pasinetti (1981). Although Pasinetti proved the existence of a natural economy, he did not demonstrate a mechanism through which a natural economy operates. Therefore, the aim of this paper is to show that this mechanism exists in a macroeconomy and to demonstrate the reasons that the mechanism holds. That is, if only one condition is not satisfied, the whole natural economy would collapse.

To keep the macroeconomic viewpoint, we adopt the fundamental equation of Kaldor $^{3}$ who is one of the most important descendent of Keyes. In addition, we introduce Riccardian price system. Riccardo is a descendent of Adam Smith.

The main results we would like to propose are following two remarks.

(1) There exists a Nash equilibrium.

(2) The Nash equilibrium corresponds to the natural economy defined by Pasinetti (1981) and Smith (1776) constructs an balanced economic growth.

(3) Therefore, there exists a mechanism by which the natural economy can operate and capitalist economy can survive.

The above conclusions demonstrate that we should take off the factors which obstruct the conditions under which the Nash equilibrium exists.

\footnotetext{
2 Pasinetti (1981), pp. 156-175.

${ }^{3}$ Kaldor (1955-1956).
} 


\section{Model}

In this section, we construct a game theoretic model with capitalists, workers and a capital distributor as players. The capital distributor is a personification of money and assets markets (known as a capital market here) and decides the distribution of capital goods between production sectors.

\subsection{Model construction}

The model contains production sectors, a price system and the fundamental equation of Kaldor's model. Let us now construct our model.

Production sectors We assume that the economy has two production sectors, a sector producing consumption goods and a sector producing capital goods. We call the former sector 0 and the latter sector 1 and allocate suffixes 0 and 1 , respectively. The technology of each sector is denoted by labour coefficient $n_{i}$ and the capital-output ratio $b_{i}(i=0,1)$. The coefficients $n_{i}$ and $b_{i}$ are positive constants. Furthermore, let $X_{i}$ and $N_{i}$ represent the output of sector $i$ and the labour employed in sector $i$, respectively. The relationship between sector $i$ 's output, $X_{i}$ and the capital stocks in sector $i, K_{i}$, is represented by

$$
X_{i}=\frac{1}{b_{i}} K_{i} . \quad(i=0,1)
$$

We denote the amount of capital stock in the economy by $K$. We further denote the ratio of the distribution of capital stock to sector 0 by $v$ and the ratio to sector 1 by $1-v$. Then, we obtain

$$
\begin{gathered}
K_{0}=v K, \\
K_{1}=(1-v) K, \\
X_{0}=\frac{1}{b_{0}} v K, \\
X_{1}=\frac{1}{b_{1}}(1-v) K .
\end{gathered}
$$

In addition, we obtain

$$
\begin{gathered}
N_{0}=n_{0} X_{0}, \\
N_{1}=n_{1} X_{1}, \\
N=N_{0}+N_{1},
\end{gathered}
$$

where $N$ is the total amount of labour employed. We now can state our assumptions about capital stock.

Assumption 1 Capital stock is never depleted.

Assumption 2 Capital stock can move freely between sector 0 and sector 1 . 
Assumption 3 Capital stock is employed completely.

By these assumptions, we obtain

$$
X_{1}=\dot{K}\left(=\dot{K}_{0}+\dot{K}_{1}\right)
$$

where dot $(\cdot)$ denotes $\cdot \equiv \frac{d}{d t}$ and $t$ denotes time. Equation (9) defines the differential equation of capital stock $K$.

Price system Let $p_{i}$ denote the price of the product of sector $i(i=0,1)$. We assume that the prices are determined as the sum of wages paid to the labour employed and the profits required to use the capital. Then, by Assumption 1, we obtain

$$
\left\{\begin{array}{l}
p_{0}=n_{0} w+\pi b_{0} p_{1} \\
p_{1}=n_{1} w+\pi b_{1} p_{1}
\end{array}\right.
$$

where $w$ and $\pi$ denote a wage rate and a profit rate, respectively. We can solve Eq. (10) to obtain ${ }^{4}$

$$
\begin{gathered}
p_{0}=\left(n_{0}+\frac{\pi n_{1} b_{0}}{1-\pi b_{1}}\right) w, \\
p_{1}=\frac{n_{1}}{1-\pi b_{1}} w .
\end{gathered}
$$

The term $\frac{n_{1}}{1-\pi b_{1}}$ in the right hand side of (12) represents the labor equivalent. ${ }^{5}$ Because prices must be positive, we assume

$$
\pi<\frac{1}{b_{1}}
$$

Equations (11) and (12) contain four variables, $p_{0}, p_{1}, \pi$ and $w$. As explained later, the profit rate $\pi$ is determined in the process of distributing capital stocks between two sectors. Therefore, the price system has one degree of freedom. Thus, we choose $p_{0}$ as the numeraire to close the price system. That is,

$$
p_{0}=1
$$

Equilibrium condition: fundamental equation of Kaldor's model When $p_{0}$ and $p_{1}$ are determined under some profit rate $\pi$ or some wage rate $w$, and $X_{0}, X_{1}, N_{0}$ and $N_{1}$ are determined in the production sectors, then GDP $Y$ which is equal to the sum of total profits $\Pi$ and total wages $W$ should be determined in the economy at the same time. This process can be explained as follows.

\footnotetext{
${ }^{4}$ The expansion of the right-hand side of (12) becomes $\frac{n_{1}}{1-\pi b_{1}} w=\left\{n_{1}+\left(\pi b_{1}\right) n_{1}+\left(\pi b_{1}\right)^{2} n_{1}+\cdots\right\} w$.

5 Pasinetti (1981), p. 43.
} 
From Assumption 1, we obtain

$$
Y=p_{0} X_{0}+p_{1} X_{1} \text {. }
$$

Substituting (1)-(5), (11) and (12) for (15), we obtain

$$
Y=\left\{\frac{\pi n_{1}}{1-\pi b_{1}} w K_{0}+\left(\frac{1}{1-\pi b_{1}}-1\right) \frac{n_{1}}{b_{1}} w K_{1}\right\}+\left(\frac{n_{0}}{b_{0}} K_{0}+\frac{n_{1}}{b_{1}} K_{1}\right) w .
$$

It is easy to verify that

$$
\begin{gathered}
W=\left(n_{0} X_{0}+n_{1} X_{1}\right) w \\
=\left(\frac{n_{0}}{b_{0}} K_{0}+\frac{n_{1}}{b_{1}} K_{1}\right) w, \\
\Pi=\pi p_{1} K_{0}+\left(p_{1} X_{1}-N_{1} w\right) \\
=\frac{\pi n_{1}}{1-\pi b_{1}} w K_{0}+\left(\frac{1}{1-\pi b_{1}}-1\right) \frac{n_{1}}{b_{1}} w K_{1} .
\end{gathered}
$$

Therefore, from Eq. (15), we obtain

$$
Y=\Pi+W .
$$

Equation (19) shows that GDP $Y$ is distributed to capitalists and workers. Therefore, from equilibrium condition, we obtain

$$
p_{1} X_{1}=s_{p} \Pi+s_{w} W
$$

where $s_{p}$ and $s_{w}$ denote the saving rates of capitalists and workers respectively and require $0 \leq s_{p} \leq 1$ and $0 \leq s_{w} \leq 1$. As explained in the following section, $s_{p}$ and $s_{w}$ are the strategies used by capitalists and workers.

Players in the macroeconomic game Now, we construct a macroeconomic model using game theory. Players are capitalists, workers and the capital distributor. As mentioned above, the capital distributor is a personification of capital market. Capitalists and workers have the objective of maximizing their profit rate and the wage rate, respectively. Therefore, we can define their problems as

$$
\begin{aligned}
& \max _{s_{p}} \pi \quad \text { s.t. } 0 \leq s_{p} \leq 1 \\
& \max _{s_{w}} w \quad \text { s.t. } 0 \leq s_{w} \leq 1
\end{aligned}
$$

where $s_{p}$ and $s_{w}$ are players' strategies. ${ }^{6}$

\footnotetext{
6 In ordinary case, the players' problems are defined by $\max _{s_{p}} \int_{0}^{\infty} e^{-\rho t} \pi d t$ and $\max _{s_{w}} \int_{0}^{\infty} e^{-\rho t} w d t$ where $\rho$ denotes the discount rate of player times. However, as shown later, the profit rate $\pi$ and the wage rate
} 
Next, we introduce Eq. (20) which is an equilibrium condition that requires the distribution of capital stock. Therefore, the economy should contain a process by which capital stocks are distributed between two production sectors. How is this distribution determined? In our game model, savings are invested in sector 1 as capital. Therefore, we set a player who decides the distribution of capital stock. We call this player capital distributor (CD). ${ }^{7}$ The CD's problem is to maximize the profit rate. In other words, the $\mathrm{CD}$ acts as a proxy for all investors in the capital market. The $\mathrm{CD}$ decides a distribution of capital stock between two production sectors with investment ratio $v$ as a strategy. We define the CD's problem as

$$
\max _{v} \pi \text {, s.t. } 0 \leq v \leq 1 \text {. }
$$

To complete the model We have now constructed the model. We have 15 unknowns, namely $X_{1}, X_{2}, p_{1}, p_{2}, K, K_{1}, K_{2}, N, N_{1}, N_{2}, w, \pi, s_{p}, s_{w} v$. For these unknowns, we have 15 equations, namely (2)-(9), (11), (12), (14) and three conditions for (20)(23). These conditions complete the equation system.

\subsection{Structure of the Model}

Let us determine the macroeconomic structure of the model which is shown in Fig. 1. GDP is produced in production sectors, namely sector 0 and sector 1 . It is distributed among capitalists and workers. They consume some part of their income. The remaining amount, i.e. savings, is invested in sector 1. Capital goods produced in sector 1 are handed to the $\mathrm{CD}$ whose problem is to decide the distribution rate $v$ to maximize the profit rate.

Because our model is constructed as a game, information structure is important. The information about the model presented in Fig. 1 is assumed to be common knowledge among the players. Namely, the game is constructed based on complete and perfect

\footnotetext{
Footnote 6 continued

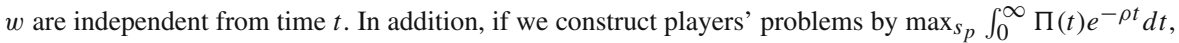
$\max _{v} \int_{0}^{\infty} \Pi(t) e^{-\rho t} d t$ and $\max _{s_{w}} \int_{0}^{\infty} W(t) e^{-\rho t} d t$, where $\Pi(t)$ and $W(t)$ denote total profits and total wages at time $t$, then the model becomes a differential game and we should solve optimal control problems. However, in such a game, it is impossible to prove the existence of balanced economic growth and its stability.

${ }^{7}$ From a macroeconomic viewpoint, three routes exist where savings circulate as investments: (i) savings $\rightarrow$ assets markets $\rightarrow$ investments, (ii) savings $\rightarrow$ financial companies (banks) $\rightarrow$ investments, and (iii) savings $\rightarrow$ financial companies $\rightarrow$ asset markets $\rightarrow$ investments. Among these, route (i) is important in a capitalist economy and is described as the CD. In addition, for example, an individual investor invests his capital in an individual firm. If this firm produces consumption goods and decides to use this investment to construct additional productive facilities, the investment should in sector 1 from a macroeconomic viewpoint. Therefore, when we construct our model with Sector 0 and Secotorl, savings should be assumed to circulate first as capital to Sector 1. And then, as capital goods produced, they are distributed by some mechanism. We trust this mechanism wherein assets markets primarily decide the distribution of capital to the $\mathrm{CD}$.
} 


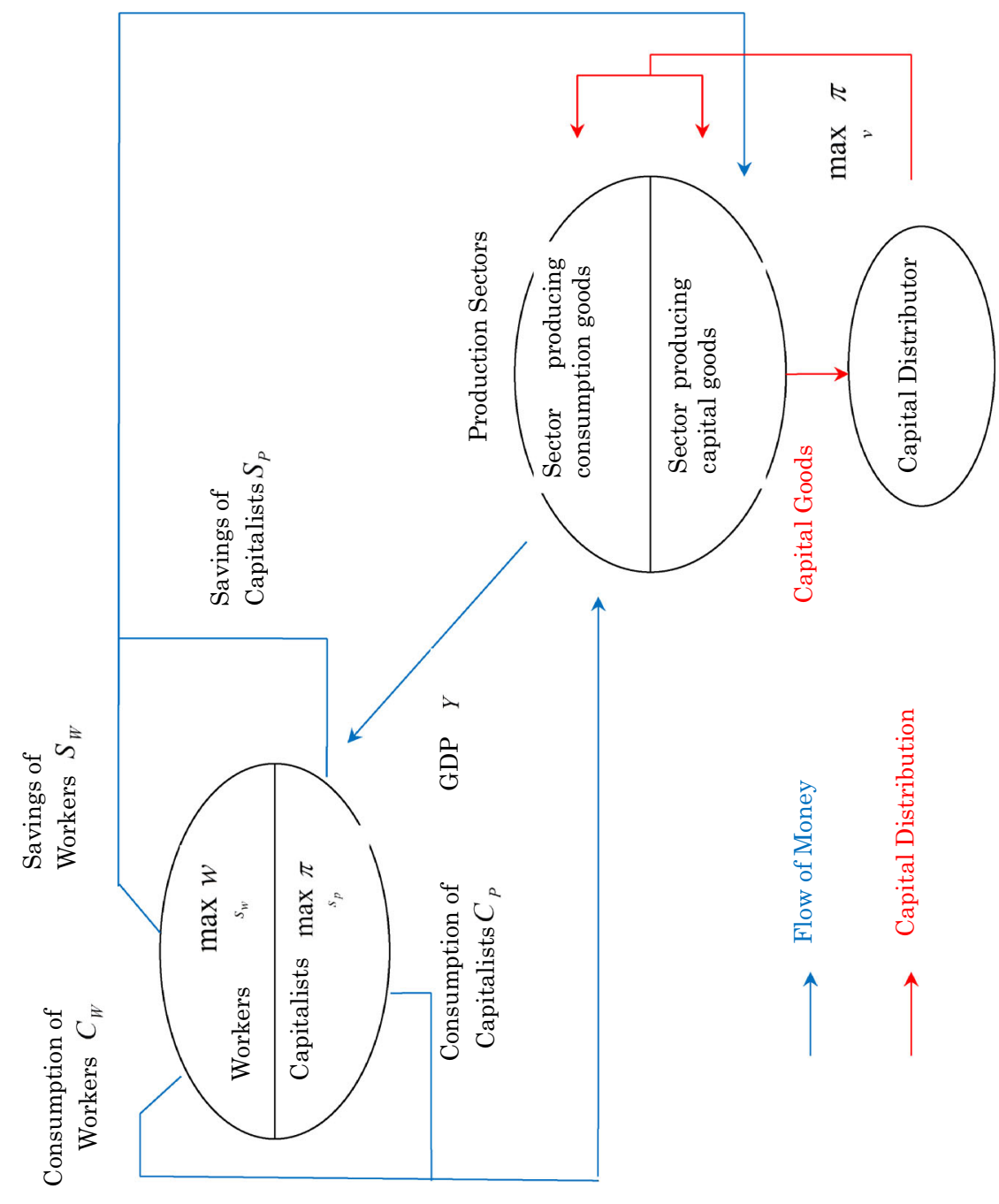

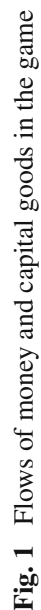


information. Decision making is achieved simultaneously. Hence, the game's solution, if it does exist, is a Nash equilibrium.

\subsection{Profit function}

Let us analyze Eq. (20). We should consider the following three cases.

$$
\text { (I) } \frac{n_{0}}{b_{0}}<\frac{n_{1}}{b_{1}}, \quad \text { (II) } \frac{n_{0}}{b_{0}}>\frac{n_{1}}{b_{1}}, \quad \text { (III) } \frac{n_{0}}{b_{0}}=\frac{n_{1}}{b_{1}} \text {. }
$$

First, we analyse cases (I) and (II). Substitute Eqs. (2) and (3) for (17) and (18). Next, substitute Eqs. (5), (12), (17) and (18) for (20) and rearrange them to obtain

$$
\pi=\frac{\frac{n_{1}}{b_{1}}\left(1-s_{w}\right)-\left\{\frac{n_{1}}{b_{1}}-\left(\frac{n_{1}}{b_{1}}-\frac{n_{0}}{b_{0}}\right) s_{w}\right\} v}{\left(s_{p}-s_{w}\right) n_{1}+b_{1} s_{w}\left(\frac{n_{1}}{b_{1}}-\frac{n_{0}}{b_{0}}\right) v}=A+\frac{B}{C+D v}
$$

where

$$
\begin{aligned}
& A=-\frac{\frac{n_{0}}{b_{0}} s_{w}+\left(1-s_{w}\right) \frac{n_{1}}{b_{1}}}{b_{1} s_{w}\left(\frac{n_{1}}{b_{1}}-\frac{n_{0}}{b_{0}}\right)}, \quad B=\frac{n_{1}\left[\frac{n_{1}}{b_{1}} s_{p}\left(1-s_{w}\right)-\frac{n_{0}}{b_{0}} s_{w}\left(1-s_{p}\right)\right]}{b_{1} s_{w}\left(\frac{n_{1}}{b_{1}}-\frac{n_{0}}{b_{0}}\right)} \\
& C=\left(s_{p}-s_{w}\right) n_{1}, \quad D=b_{1} s_{w}\left(\frac{n_{1}}{b_{1}}-\frac{n_{0}}{b_{0}}\right) .
\end{aligned}
$$

Equation (24) expresses a hyperbola of the variable $v$. Although $A, B, C$ and $D$ contain the strategies of players, $s_{w}, s_{p}$, we may depict the graph of (24) as shown in Fig. 2, considering $s_{w}, s_{p}$ as parameters. The 'plus or minus' sign on $A, B, C$ and $D$ depend on the conditions of the technical coefficients. We show the graphs in the case of (I).

Because we can depict the graph of (24) in the case of (II) in the same way, we do not show it here.

Finally, we analyze the case of (III). Substitute Eqs. (5), (12), (17) and (18) for (20) and rearrange them to obtain

$$
\pi=\frac{1-s_{w}}{\left(s_{p}-s_{w}\right) b_{1}}-\frac{1}{\left(s_{p}-s_{w}\right) b_{1}} v .
$$

We depict the graph in the case (III) in Fig. 3.

\subsection{Analysis}

We now presented all the information necessary to analyze the game. We present the following proposition. 
(a) The case of $B>0, \quad s_{p}>s_{w}$

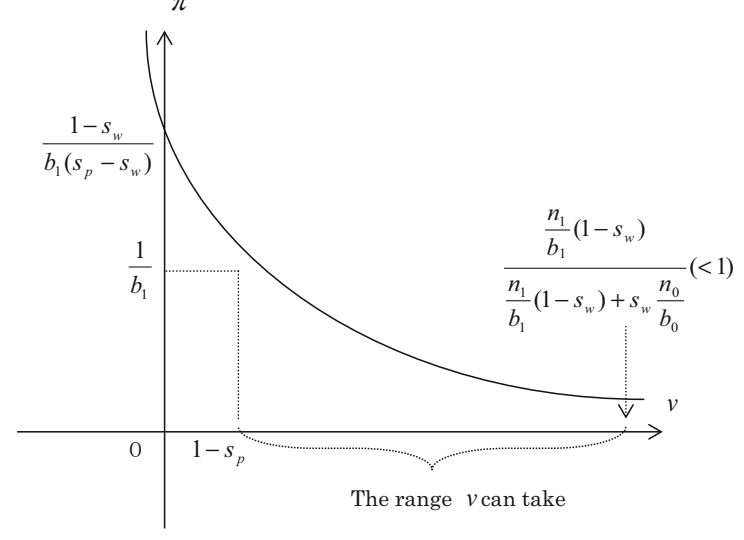

(b) The case of $B>0, \quad s_{p}<s_{w}$
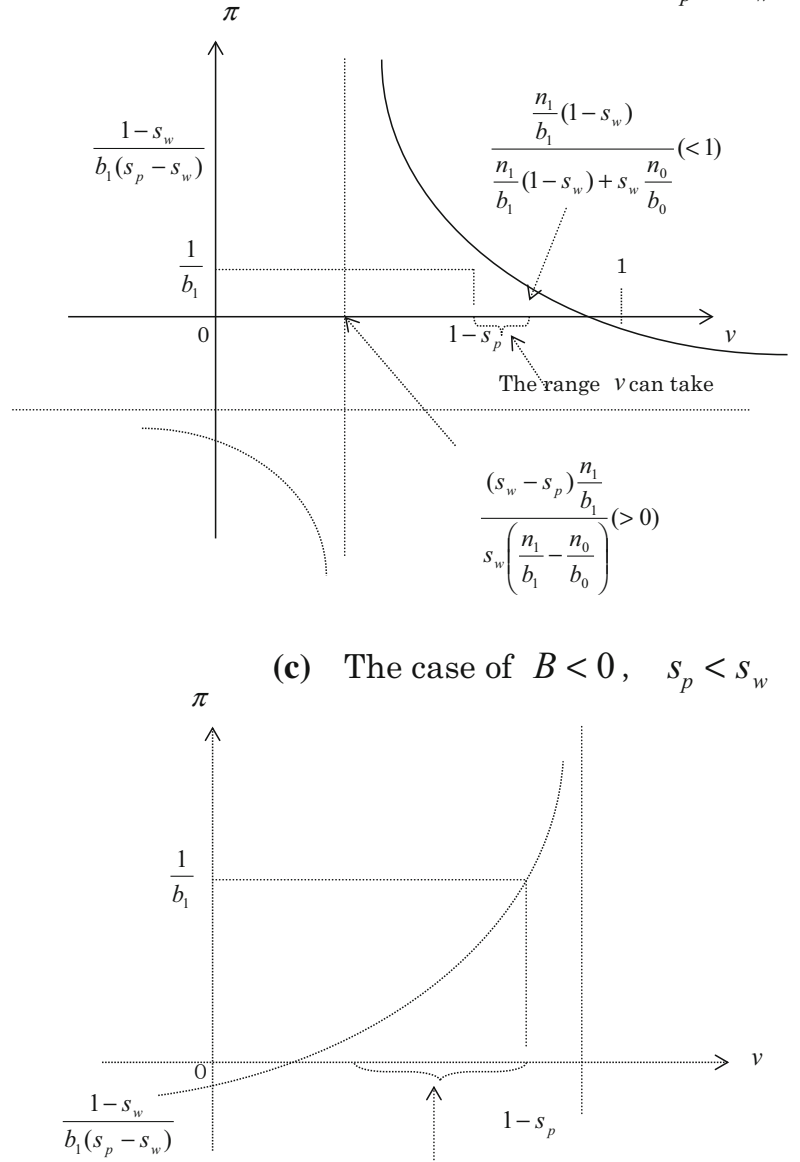

The range $v$ can take

Fig. 2 Profit function in the case of (I) 


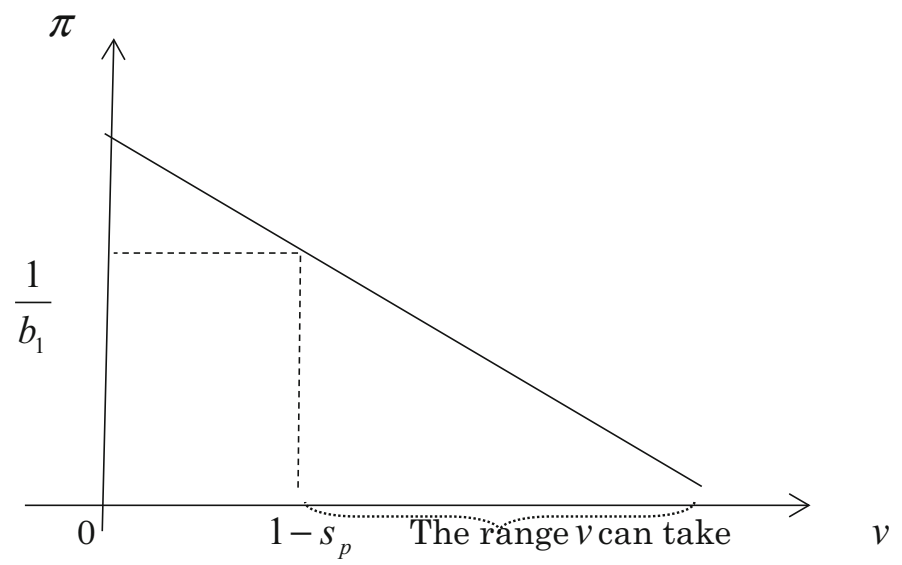

Fig. 3 Profit function in the case of (III)

Proposition 1 (Nash Equilibrium)

(i) Equation (26) is a Nash equilibrium.

$$
\left(s_{w}^{*}, s_{p}^{*}, \quad v^{*}\right)=\left(\frac{n_{1}}{n_{0}+n_{1}}, \frac{b_{1}}{b_{0}+b_{1}}, \frac{b_{0}}{b_{0}+b_{1}}\right) .
$$

(ii) The profit rate and wage rate under (26) are

$$
\left\{\begin{array}{l}
\pi^{*}=\frac{1}{b_{0}+b_{1}} \\
w^{*}=\frac{1}{n_{0}+n_{1}} .
\end{array}\right.
$$

Proof (i) We show that each player's strategy is the best response to the other players' strategies in Eq. (26).

(1) Suppose that the strategies $s_{p}^{*}$ and $v^{*}$ are given. Substituting $v^{*}=1-s_{p}^{*}$ for Eq. (24), we obtain $\pi=\frac{1}{b_{1}}$ (see Fig. 2). On the other hand, we obtain the wage-profit curve

$$
\pi=\frac{1-n_{0} w}{b_{1}+\left(n_{1} b_{0}-n_{0} b_{1}\right) w}
$$

from Eq. (14). Then, the wage rate $w$ is equal to 0 . Workers intend to avoid $w=0$. However, only one strategy enables workers to avoid it. In other words, workers only need to take the strategy that brings about $B=0$ in Eq. (24). This condition is denoted by

$$
\frac{n_{1}}{b_{1}} s_{p}\left(1-s_{w}\right)=\frac{n_{0}}{b_{0}} s_{w}\left(1-s_{p}\right) .
$$

Therefore, the workers should take the strategy $s_{w}^{*}$ in response to capitalists' strategy $s_{p}^{*}$.

However, the workers should analyze what happens in the game and calculate their payoff for Eq. (26). Next, we analyze these points [see Eq. (24)]. For Eq. (26), 


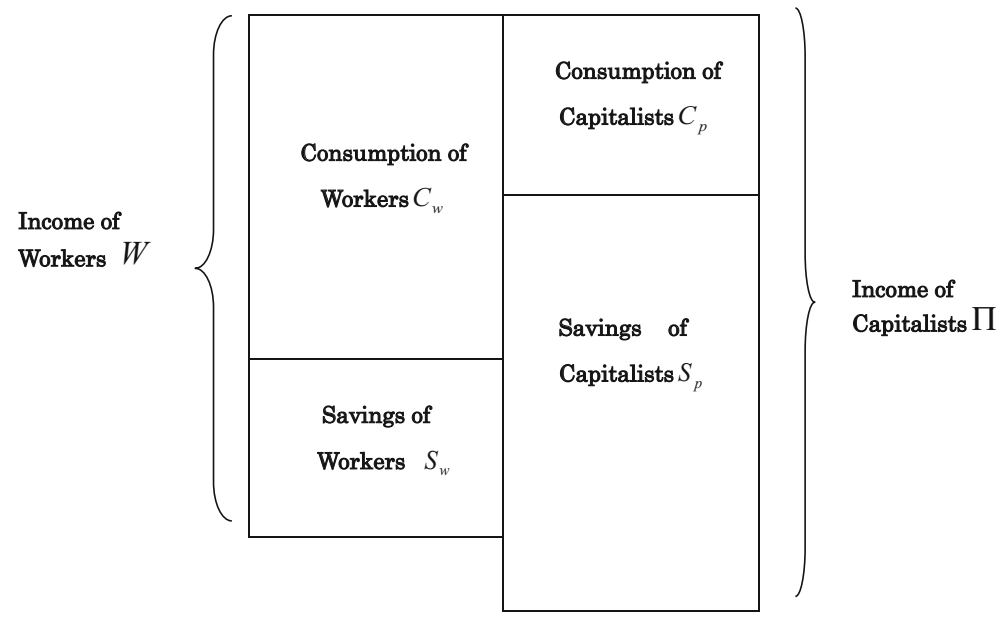

Fig. 4 Players' consumptions and savings

$B=0$ and $C+D v=0$. Therefore, the players cannot determine the profit rate in the game. Then, what happens in the game? The fact that the profit rate cannot determined in the game implies that its determination depends on conditions of the money market.

Figure 4 shows the balance between the demand and supply of money. Firstly, the capitalists should spend part of their income on consumption. In Fig. 4, the capitalists' consumption is denoted by $C_{p}$ which is considered as a shortage of capital. In our model, this shortage should be supplied in the money market where workers supply capital. ${ }^{8}$ Thus, workers' savings which are denoted by $S_{w}$ in Fig. 4 are supplied as capital in the money market. Therefore, we obtain

$$
C_{p}=S_{W}
$$

By definition, $C_{p}=\left(1-s_{p}\right) \Pi, S_{w}=s_{w} W$. Thus, we obtain

$$
\pi=\frac{1}{b_{0}+b_{1}}
$$

by using Eqs. (17), (18) and (26). ${ }^{9}$ Substituting Eqs. (31) for (28), we obtain $w^{*}$ in Eq. (26). Therefore, we can conclude that $s_{w}^{*}$ is the best response to $\left(s_{p}^{*}, v^{*}\right)$.

\footnotetext{
8 From a macroeconomic viewpoint, there are three routes where savings circulate as investments. See Footnote 7. In this case, money flows through either route (ii) or route (iii).

9 Equation (30) denotes a balanced condition between the supply of and the demand for money. Therefore, Eq. (31) means interest rate and not profit rate. Players' strategies yield Eq. (31) and they should follow this rate in the game. However, as a result, the interest rate which players follow coincides with the profit rate that guarantees balanced economic growth and a natural economy (see Propositions 2 and 3). Regarding natural rate interest, see Pasinetti (1981) VIII.
} 
(2) Suppose that the strategies $s_{w}^{*}$ and $v^{*}$ are given. Then, the profit rate is $\pi=0$, because the numerator of Eq. (24) becomes zero. Capitalists intend to avoid $\pi=0$. For this purpose, capitalists should choose the strategy that satisfies $C+D v=0$ for $s_{w}^{*}$ and $v^{*}$. Accordingly, the capitalists' strategy is given by $s_{p}^{*}$ in Eq. (26). However, the capitalists should analyze what happens in the game and calculate their payoff for Eq. (26).

In this case, players are also unable to determine the profit rate in the game. Therefore, capitalists should calculate their payoff using Eq. (30) and recognizes that they can obtain Eq. (31). Thus, we can conclude that $s_{p}^{*}$ is the best response to $\left(s_{w}^{*}, v^{*}\right)$.

(3) Suppose that the strategies $s_{w}^{*}$ and $s_{p}^{*}$ are given. In this case, we obtain $B=0$.In the case of (I), we obtain $\pi=A<0$ in Eq. (24). Therefore, the CD intends to avoid a situation where the profit rate is determined by Eq. (24). For this purpose, the CD should choose the strategy $v$ that satisfies $C+D v=0$ in Eq. (24); this strategy is given by $v^{*}$ in Eq. (26). In this case, players are also unable to determine the profit rate in the game. Therefore, the CD's payoff can be calculated using Eq. (30) and players should recognizes that they can get Eq. (31). Thus, we can conclude that the strategy $v^{*}$ is the best response to $\left(s_{w}^{*}, s_{p}^{*}\right)$.

In the case of (II), if the CD does not choose strategy $v^{*}$, then the profit rate becomes

$$
\pi=A=\frac{1}{b_{1}}+\frac{n_{1}}{b_{1}^{2}\left(\frac{n_{0}}{b_{0}}-\frac{n_{1}}{b_{1}}\right)}>\frac{1}{b_{1}} .
$$

This condition is not allowed in the game. See inequality (13). The CD can recognizes this situation as a player of the game. Therefore, the CD should choose strategy $v^{*}$.

In the case of (III), condition (29) becomes $s_{p}=s_{w}$. We can analyze it in the same manner as case (I) and obtain the same conclusion.

The Nash equilibrium also constructs balanced economic growth. We offer a proposition regarding this point.

Proposition 2 (Balanced Economic Growth) The Nash equilibrium in Eq. (26) constructs balanced economic growth. The rate of this balanced economic growth $g$ is $g=\frac{1}{b_{0}+b_{1}}$ and the balanced economic growth vector is $\left(\begin{array}{l}b_{0} \\ b_{1}\end{array}\right)$.

Proof First, let us consider the sustainability of the game's two production sectors. Note that sector 1 provides sector 0 with capital goods. Therefore, if a balanced economic growth path exists, the following condition is required,

$$
\dot{X}_{0}=\dot{X}_{1}
$$

Equation (32) is supported by $v^{*}$ in (26), because we obtain

$$
\frac{\dot{K}_{0}}{\dot{K}_{1}}=\frac{v}{1-v}=\frac{b_{0}}{b_{1}}
$$


from $v=v^{*}, K_{0}=v K, K_{1}=(1-v) K$ and also obtain

$$
\dot{X}_{0}=\frac{\dot{K}_{0}}{b_{0}}=\frac{\dot{K}_{1}}{b_{1}}=\dot{X}_{1}
$$

from Eqs. (1) and (33). Therefore, $v^{*}$ guarantees the condition required for balanced economic growth.

Next, let us construct the balanced economic growth path. From Eqs. (3) and (9), we obtain

$$
\frac{\dot{K}}{K_{1}}=\frac{1}{b_{1}}
$$

On the other hand, from $K_{0}=v K$ and $K_{1}=(1-v) K$, we obtain

$$
\begin{aligned}
& \dot{K}_{0}=v \dot{K}=\frac{v}{b_{1}} K_{1}, \\
& \dot{K}_{1}=(1-v) \dot{K}=\frac{(1-v)}{b_{1}} K_{1} .
\end{aligned}
$$

These equations can be denoted by

$$
\left[\begin{array}{c}
\dot{K}_{0} \\
\dot{K}_{1}
\end{array}\right]=M\left[\begin{array}{l}
K_{0} \\
K_{1}
\end{array}\right], \quad \text { where } M=\left[\begin{array}{cc}
0 & \frac{v}{b_{1}} \\
0 & \frac{1-v}{b_{1}}
\end{array}\right] \text {, }
$$

Calculating the eigenvalues and eigenvectors of the matrix $M$, we obtain

$$
\lambda_{0}=0, \quad \lambda_{1}=\frac{1-v}{b_{1}}
$$

and

$$
h_{0}=\left[\begin{array}{l}
0 \\
0
\end{array}\right], \quad h_{1}=\left[\begin{array}{c}
\frac{v}{b_{1}} \\
\frac{1-v}{b_{1}}
\end{array}\right]
$$

where the eigenvector $h_{i}$ corresponds to the eigenvalue $\lambda_{i}(i=0,1)$. Therefore, the capital vector that denotes the balanced economic growth is

$$
\left[\begin{array}{l}
K_{0} \\
K_{1}
\end{array}\right]=\bar{K} \exp \left\{\left(\frac{1-v}{b_{1}}\right) t\right\}\left[\begin{array}{c}
\frac{v}{b_{1}} \\
\frac{1-v}{b_{1}}
\end{array}\right]
$$

where $\bar{K}$ denotes the initial level of capital stock. On the balanced economic growth path, it is easily verified that

$$
\frac{\dot{K}_{0}}{K_{0}}=\frac{\dot{K}_{1}}{K_{1}}=\frac{1}{b_{1}}(1-v) .
$$


Furthermore, the growth rate of the capital stock $\frac{\dot{K}}{K}$ is calculated as follows,

$$
\frac{\dot{K}}{K}=\frac{\dot{K}_{0}+\dot{K}_{1}}{K_{0}+K_{1}}=\frac{\frac{\dot{K}}{K_{1}}}{1+\frac{K_{0}}{K_{1}}}=\frac{1}{b_{1}\left(1+\frac{K_{0}}{K_{1}}\right)}=\frac{1-v}{b_{1}} .
$$

Substituting $v^{*}$ for Eqs. (35) and (36), we obtain

$$
\frac{\dot{K}}{K}=\frac{\dot{K}_{0}}{K_{0}}=\frac{\dot{K}_{1}}{K_{1}}=\frac{1}{b_{0}+b_{1}} .
$$

From Eqs. (1) and (37), we obtain

$$
\frac{\dot{X}_{0}}{X_{0}}=\frac{\dot{X}_{1}}{X_{1}}=\frac{1}{b_{0}+b_{1}}=g
$$

\subsection{Natural Economy}

Now we analyze a natural economy, first with a definition of natural economy using concepts of Smith (1776) and Pasinetti (1981).

Definition 1 (Natural Economy) If an economy satisfies the following conditions, we call it a natural economy.

(i) A natural price, defined by Smith, is established in the price of a commodity.

(ii) The price of capital goods follows a pure labour theory. ${ }^{10}$

(iii) Total profit is equal to total savings, and total wages is equal to total consumption. $^{11}$

(iv) The profit rate is equal to the (balanced) growth rate of the economy. ${ }^{12}$

We prove that the Nash equilibrium (26) satisfies conditions (i), (ii), and (iii). However, for reparations in advance, we consider the natural price as defined by Adam Smith. In particular, see the following sentences, regarding the natural wage rate.

"There is in every society or neighborhood an ordinary or average rate both of wages and profit in every different employment of labour and stock. This rate is naturally regulated, partly by the general circumstances of the society, and partly by the particular nature of each employment. ${ }^{13}$ Thus far at least seems certain, that, in order to bring up a family, the labour of husband and wife together

\footnotetext{
10 Pasinetti (1981), pp. 131-133.

11 Ibid., p. 147.

12 Ibid., pp. 128-131.

13 Smith (1776), Chapter VII, p. 55.
} 
must, even in the lowest species of common labour, be able to earn something more than what is precisely necessary for their own maintenance; but in what proportion, whether in that above mentioned, or in any other, I shall not take upon me to determine." 14

We should precisely verify this point, using our model. We adopt consumption goods as a numeraire and set Eq. (14). That is, wage rates, profit rates, and capital stock are measured by consumption. At this stage, suppose that $X$ units of labor, required to be input, produce one unit of consumption goods, and that the wage rate is $w$. Then, Eq. (14) should be precisely analyzed.

(I) The technology of the economy we are considering requires $X$ units of inputted labor to produce one unit of consumption goods.

(II) Workers maintain their lives by consuming.

(III) Therefore, the natural wage rate implies that $X$ units of labor should be maintained by consuming one unit of goods. That is, a worker and his (or her) family should be maintained by the natural wage rate. This implies that the natural wage rate $w$ is $w=\frac{1}{X}$.

Therefore, to prove that the Nash equilibrium (26) establishes a natural economy, we should demonstrate that the price of consumption goods is accurately expressed by the quantity of labor input.

On the other hand, Adam Smith took care to not commit himself regarding the level of the natural profit rate. We quote him again:

"Profit is so very fluctuating, that the person who carries on a particular trade cannot always tell you himself what is the average of his annual profit.-It varies, therefore, not only from year to year, but from day to day, and almost from hour to hour." 15

These sentences imply that Adam Smith's analysis was concentrated on the mechanisms of the market.

In contrast, Pasinetti (1981) precisely defined a natural profit rate based on macroeconomics. A production process and an economic structure of economy lie behind Pasinetti's ${ }^{16}$ definition of natural profit rate. We quote him, first, regarding the natural rate of profit:

"Now that a natural rate of profit is introduced, all relations become much more straightforward. The theory of value implied by the present theoretical scheme becomes a theory in terms of simple labour-a pure labour theory of value."17

In addition, it is important to understand the meaning of the natural profit rate from a macroeconomic viewpoint. ${ }^{18}$

Next, we offer a proposition regarding the natural economy.

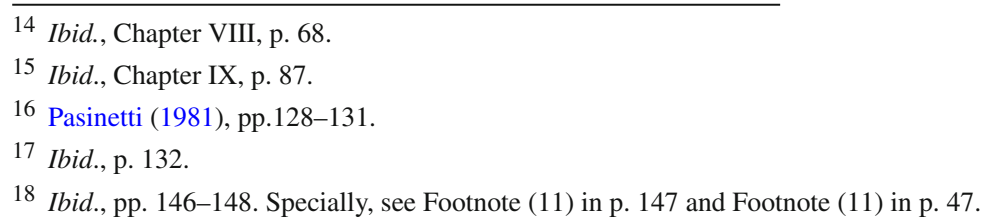


Proposition 3 (Natural Economy) The Nash equilibrium in Equation (26) constructs a natural economy.

Proof we indicate that the Nash equilibrium in Eq. (26) satisfies the conditions of $a$ natural economy.

(i) Substituting $\pi^{*}$ in (27) for (11), we obtain $p_{0}=\left(n_{0}+n_{1}\right) w$. Notice that the term $n_{1} w$ on the right-hand side of this equation is paid to capitalists as profit. However, this part is paid to workers to produce one unit of capital goods, which is required to produce consumption goods. That is, $p_{0}$ purely expresses the quantity of labor input in the economy. By (14), the wage rate corresponding to $\pi^{*}$ is $w^{*}$, in (27). The wage rate $w^{*}$ implies that one unit of consumption goods should sustain $\left(n_{0}+n_{1}\right)$ units of labor.

(ii) Next, we analyze $\pi^{*}$ in Eq. (27). As shown in Footnote 9, it is the interest rate determined by the players' strategies and Eq. (30). Players should follow in this rate in the game. However, as shown in Proposition $2, \pi^{*}$ is equal to the balanced economic growth rate carried out by the Nash equilibrium. In addition, suppose that one unit of consumption goods and one unit of capital goods are produced. Production requires $b_{0}+b_{1}$ units of capital goods. In this roundabout production process, $\frac{1}{b_{0}+b_{1}}$ constitutes the additional social cost that the economy should pay. ${ }^{19}$ In the growing economy, $\frac{1}{b_{0}+b_{1}}$ implies the natural profit rate. ${ }^{20}$ Therefore, as a result, $\pi^{*}$ coincides with the natural profit rate defined by Pasinetti $(1981)^{21}$

Using these preparations, we expand the right-hand side of Eq. (12), according to its Footnote 4. Substituting the profit rate $\pi^{*}$ for Footnote 4, we obtain

$$
p_{1}=n_{1}\left\{1+\left(g b_{1}\right)+\left(g b_{1}\right)^{2}+\left(g b_{1}\right)^{3}+\cdots \cdots \cdot \cdot\right\} w
$$

Equation (39) does not express a labor equivalent but rather a pure labor theory corresponding to the balanced economic growth. ${ }^{22}$

(iii) Next, we prove that the Nash equilibrium (26) satisfies one of the conditions of natural economy defined by Pasinetti. ${ }^{23}$ We quote Pasinetti (1981).

In the 'natural' economic system, total profits turn out to be equal to total savings, and total wages turn out to be equal to total consumption. ${ }^{24}$ Total profits emerge as a kind of prior claim to share in the final national income, whilst total wages emerge as a kind of residual or 'surplus' that remains over and above what has been charged for profit. ${ }^{25}$

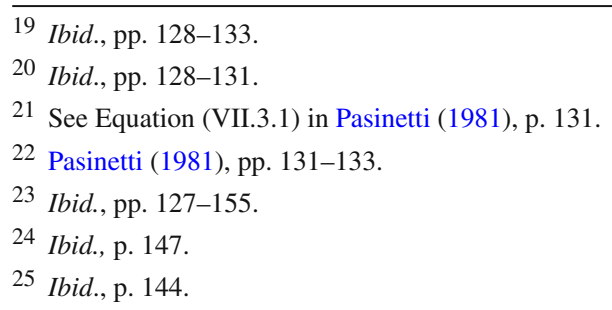


The Nash equilibrium in Eq. (26) brings about Eq. (27). We indicate that Eq. (27) satisfies the Pasinetti's condition. From Eq. (30) where $C_{p}=\left(1-s_{p}\right) \Pi, S_{w}=$ $s_{w} W$, we obtain

$$
p_{0} X_{0}=\left(1-s_{p}\right) \Pi+\left(1-s_{w}\right) W=W .
$$

From Eqs. (15), (19) and (40), we obtain

$$
p_{1} X_{1}=\Pi \text {. }
$$

In the process of the above calculation, the profit rate is determined prior to the wage rate. Therefore, total wages are interpreted as a surplus that remains over and above what has been charged for profit. ${ }^{26}$ Therefore, the economic result (27) involves a character of the natural economy defined by Pasinetti (1981) ${ }^{27}$ (iv) It is apparent from above analysis.

Finally, we obtain the following proposition which indicates the relationships between the Nash equilibrium and the technological coefficients of the two production sectors.

Proposition 4 (Production Structure and Saving Rate in a Nash Equilibrium) In the Nash equilibrium in Eq. (26), we obtain the following conditions.

$$
\begin{aligned}
& \text { If } \frac{n_{0}}{b_{0}}<\frac{n_{1}}{b_{1}} \text {, then } s_{w}^{*}<s_{p}^{*} \text {, } \\
& \text { if } \frac{n_{0}}{b_{0}}>\frac{n_{1}}{b_{1}} \text {, then } s_{w}^{*}>s_{p}^{*} \text {, }
\end{aligned}
$$

and

$$
\text { if } \frac{n_{0}}{b_{0}}=\frac{n_{1}}{b_{1}} \text {, then } s_{w}^{*}=s_{p}^{*} \text {. }
$$

Proof We obtain Proposition 4 from Eq. (26) directly.

Proposition 4 indicates the relationships between production structures and the players' saving rates. However, we should note the relationship between Proposition 4 and Pasinetti's analyses. Pasinetti (1962) proved that the condition $s_{w}<s_{p}$ was necessary for the macroeconomy to be stable. Let us consider this problem.

Remember that Kaldor's fundamental Eq. (20) constructs a central core of Keynesian economy and requires $s_{w}<s_{p}$ for the economy to be stable.

\footnotetext{
26 Ibid., p. 144.

27 Ibid., pp. 127-133.
} 


\subsection{A Caution for Deviation from Natural Economy}

At this stage, we should analyze the background of Proposition 4. The problem is the Nash equilibrium in Eq. (26). It rejects the proposition that the profit rate is determined by the profit function in Eq. (24), which is constructed from Kaldor's fundamental Eq. (20). In other words, if the profit rate is determined by the profit function, each player is placed in a worse situation. Therefore, the Nash equilibrium makes Eq. (20) the identity, or $1=1$, and avoids the profit rate being determined by Eq. (24). As a result, in the Nash equilibrium, the profit rate is determined at a level where capitalists' consumption is provided by workers' savings. This condition has a common feature with Wicksell's natural interest rate. ${ }^{28}$

We construct our model using Kaldor's fundamental equation. However, the Keynesian equation causes a condition where it does not function. As a result, it brings about a classical profit rate. Proposition 4 is organized on the basis of this condition. We conclude that the outcome of capitalists' or workers' savings rates, whichever is larger, depends on the technological structure of the two production sectors.

This analysis implies that if only one condition is destroyed, the whole economy would lose its balance. From the above discussion, one disturbing factor for a natural economy makes its appearance: Kaldor's fundamental Eq. (20) would revive to determine profit and wage rates. Remember the proof of the Nash equilibrium: capitalists have a strong strategy that yields $\pi=\frac{1}{b_{1}}$ and $w=0$. Workers have a defensive strategy that satisfies Eq. (29). This means that if the natural economy is destroyed, workers have their backs against the wall. From a macroeconomic viewpoint, the balance in income distribution is completely destroyed. This is the start of an economic crisis. ${ }^{29}$

\section{Conclusion}

Using game theory, we proved that a natural economy is operated in macroeconomy. This study is based on the awareness of the issue discussed in Akimoto (2014), namely that the fundamental cause of the current economic crisis is a large deviation from the natural economy. However, some limitations to our findings should be discussed.

First, we should point out that the game-model in this paper does not involve innovations. In other words, as is shown in Eqs. (1), (7) and (8), the model is constructed using the fixed technological coefficients. However, as Schumpeter noted, "the fundamental impulse that sets and keeps the capitalist engine in motion comes from the new consumers' goods, the new methods of production or transportation, the new markets, the new forms of industrial organization that capitalist enterprise creates". 30 This is the fundamental phenomenon of economic development. ${ }^{31}$ Therefore, the assumption of fixed technological coefficients should be removed. Regarding this point, $r$ the study by Pasinetti (1981) constructed the vertically integrated analysis that enabled

\footnotetext{
28 Wicksell (1898), Chapter VIII.

29 Akimoto (2014).

30 Schumpeter (1954), p. 83.

31 Schumpeter (1934), II.
} 
innovations to be examined. Therefore, we should integrate the vertically integrated analysis into our game-model.

Second, we should once again designate the importance of the natural economy. Although many important studies regarding the natural economy exist, few examine the risk of deviating from the natural economy. As Akimoto (2014) indicated, the rapid increase in monetary assets can cause an imbalance between the real economic sector and the monetary sector. This imbalance implies a deviation from the natural economy and serves as a fundamental cause of economic crises. This source of risk should be studied from various points of view.

This study thus illustrates that the problem of whether the natural economy can be produced in a macroeconomy that involves innovation and technological change still needed to be examined. The game-model in this paper excluded these factors a priori. If the natural economy cannot operate in a macroeconomy involving innovation, we should examine the conditions and policies which support the natural economy. We will examine this problem in an upcoming paper.

\section{References}

Akimoto K (2014) A fundamental cause of economic crisis; a macroeconomic game between the real economic sector and monetary sector. Int J Econ Sci III(4):1-37

Kaldor N (1955-1956) Alternative Theories of distribution. Rev Econ Stud 23:83-100

Keynes JM (1930) A treatise on money II; the applied theory of money. The Macmillan and Co., Ltd, London

Pasinetti LL (1962) Rate of profit and income distribution in relation to the rate of economic growth. Rev Econ Stud, vol xxix (3), No 81

Pasinetti LL (1981) Structural change and economic growth; a theoretical essay on the dynamics of the wealth of nation. Cambridge University Press, London

Schumpeter JA (1934) The theory of economic growth. Harvard University Press, Cambridge

Schumpeter JA (1954) Capitalism, socialism and democracy, fourth edition, London. George Allen \& Unwin: first edition, Harper \& Row 1942, New York

Smith A (1776) An inquiry into the nature and causes of the wealth of nations', edited, with an introduction, notes, marginal summary and an enlarged index by Edwin Cannan. LL.D. Modern Library Edition, New York, 1937

Wicksell JFK (1898) Geldzins und Güterpreise, Eine Studie über die den Tauschwert des Geldes bestimmenden Ursachen, Jena (English version: Interest and Prices, A Study of the Causes Regulating the Value of Money, translated by R.F. Kahn, Macmillan, London, 1936) 